\title{
Introductory remarks to the Special Issue on Social Implications of Technology, in Honor of the Late Dr. Lodewijk Bos
}

\author{
Luis Kun ${ }^{1}$
}

Received: 1 March 2016 /Accepted: 2 March 2016/Published online: 12 April 2016

(C) IUPESM and Springer-Verlag Berlin Heidelberg 2016

Drs. Lodewijk Bos and I were Co-Editors-In-Chiefs, for this - multi-disciplinary and inter-disciplinary Journal of IUPESM + Springer + WHO from the moment it was conceived in 2010. He was a man of immense dedication and passion and above all a great friend and professional.

Many of you may have wondered: who was Lodewijk Bos? The following paragraphs, taken from his Eulogy [1] may offer a better understanding on who he was for those that never had the opportunity to meet him:

"Lodewijk Bos was a person of vision who understood strategy very well. He was a trusted individual and his integrity and quality of outcomes were unsurpassed. Yet his operational capacity, to me, was one of the most impressive characteristics he had and that I have ever encountered before I met him. It was always a pleasure discussing with him any type of challenge we encountered because of his disposition to listen and to implement quickly whatever was decided or needed. For example due to his effort, personal involvement and commitment, every time you attended the ICMCC annual conference, as you registered the first day to the meeting, you were given a hard-bound book which contained all the papers to be presented.

This article is part of the Topical Collection on Social Implications of Technologies

Luis Kun

LuisKun893@gmail.com

1 Washington, D.C., USA
After Swamy died in 2005, the "Swamy Laxminarayan Lecture" was created and the first to deliver this keynote was Prof. Brian O'Connell, former President of the IEEE Society of Social Implications of Technology (SSIT). Unfortunately, Brian died shortly after this event and within 24 hours of my informing Lodewijk, the ICMCC website posted news of Brian's death and an account of his professional life.

In June 2009 my colleague Robert Mathews and I put together an Interoperability Summit entitled Healthcare Reform or Healthcare Transformation at the National Academy of Science / Engineering in Washington DC. About 30 professional organizations (i.e., ICMCC, IFMBE, SSIT, AIMBE, EMBS, Computer Society, etc.) and 23 different Federal Agencies / Departments attended as well as many of you. Lodewijk's website was the first place where any type of comments regarding this meeting was published.

In March 2011, during the Fukushima earthquake - tsunami and later nuclear / radiation crisis, through the IFMBE Global Citizen Safety and Security Working Group I was trying to help colleagues and the people from Japan. I spoke with Lodewijk and within 24 hours he had at the ICMCC website a blog where individuals could ask questions and relevant materials could be shared."

\section{Time evolution of Lodewijk's thinking ...}

In 2011 I had the privilege of co-editing with Lodewijk the book: "Future Visions of Biomedicine and Bioinformatics" [2]. Lodewijk wrote in the introductory words a Tribute to 
Swamy Laxminarayan (the person that we were honoring with that publication) admitting that he was a complete stranger to the area of health technology, but wanted to "organize a conference looking from the ICT angle towards the fields of medicine and care".

Lodwijk Bos in just a very few years, less than a decade, was able to become an expert in the field, influencing tremendously the thinking and intellect of many. He was a very fast learner. He connected people from around the world, using the same tools that he spoke and wrote about. While acquiring and incorporating new concepts he challenged the system and the status- quo frequently.

In order for you to understand how he evolved intellectually, I have assembled a few paragraphs showing his involvement in the field in the 2004 - 2011 timeframe, year in which we started as Co-Editors in Chief of this journal. It is important for you the reader to note, that all the areas mentioned in this evolution, are represented in this Special Issue of the Journal.

Lodewijk became in 2004 the founding president of the International Council on Medical and Care Compunetics (ICMCC) a foundation dealing with the social, societal, and ethical aspects of the use of computing and networking (compunetics) in medicine and care.

In his historic overview of ICMCC [3], Lodewijk explained that the initial focus was on two points: awareness and the supply of validated information targeting both patients and professionals. Soon after, two more items were added: electronic records and digital homecare. By 2006, the first form of Internet knowledge center was created (Record Access Portal [4]), with their guidelines later listed on Patient Record Access to the WHO [5].

In the first meeting of the ICMCC, a paper entitled "Healthcare Compunetics" [6] explained their vision:

"Changes in life expectancy, healthy life expectancy and health seeking behaviors are heavily impacting the demand for care. Such changes could occur across the whole population or for specific groups. Changes for specific groups will be particularly affected by policy initiatives, while both these and wider changes will be affected by people's levels of engagement with their health and the health service itself. Levels of education, income and media coverage of health issues are also important. These factors could also encourage an increase in people caring for themselves and their families or community.

People are now expecting a patient-centered service with safe high quality treatment, comfortable accommodation services, fast access and an integrated joined-up system. The uptake of integrated Information and Communication technologies (ICT) will be crucial.
Healthcare Compunetics, the combination of computing and networking customized for medical care, will provide the common policy and framework for combined multi-disciplinary research, development, implementation and usage."

In 2007, in his introduction to "Medical and Care Compunetics the Future of Patient-Related ICT" [7], Lodewijk explained the etymology of the word Compunetics:

"The word Compunetics is derived from the combination of Computing and Networking, but the new term allowed including social aspects, becoming "computing and social and technical networking". Now, three years after the introduction of the word, it can be defined as the field concerned with the social, societal and ethical implications of computing and networking (COMPUting \& Networking, its EThICs and Social/societal implications."

Also in 2007, the ICMCC News Page was started, and it became one of the leading sources of news on health information technology in the Internet.

By 2008, we had our annual ICMCC Event in the UK, hosted by the University of Westminster Business School. In "The Impatient Patient" [8], the authors explained:

"Modern Healthcare Systems that have embraced ICT and Internet technologies (referred as Health $1,0)$ are evolving towards self-management but from a clinical knowledge perspective. In contrast, from a user experience perspective, and using the latest web 2.0 technologies, the developing healthcare social networking communities (referred as Health 2.0) are evolving towards becoming online medical portals. The growing Grand Challenge for healthcare is therefore: how will health care services (Health 1.0) work together with user-generated health care (Health 2.0) in a consumer market place delivering self-management services for a healthier lifestyle and medical compliance. What is foreseen is that the selfcare information tool of the future will be a combination between the patient's observation record and the Internet, with the doctor and the patient positioned together at the intersection but not having to pay attention to the technology. This article deals with the various aspects related to this Grand Challenge like the paradigm shift towards a needsled and consumer-oriented healthcare, the role, supply and quality of information and the changing doctor-patient relationship." 
In the Introduction to the Handbook of Digital Homecare [9], the authors explained:

"As a new form of care, digital homecare is in essence the consequence of "the changing nature of health and medical practice itself [...]. This shift from an acute inpatient treatment to chronic, community based, guided self-care and health risk management will demand unique advances from the information technologies." ...With the upcoming importance of genomics, future developments such as personalized medicine will most definitely become an important part of digital homecare. Digital homecare benefits a very diverse "audience". Due to an increasingly ageing population combined with a growing scarcity in professional resources, the elderly are and will become more and more one of the largest target groups for digital homecare. In addition "patients with chronic conditions could benefit the most from digital homecare, like patients with hypertension, diabetes, heart failure and coronary artery disease, stroke, chronic pain, wounds, depression and mental health problems, dementia and palliative care and fall risk. A third category of people that will seriously benefit from digital homecare are the disabled and those who can benefit from tele-rehabilitation programs. [...] Care providers also benefit from shifting the Point of Care to the patient's home and remotely monitor and care for them. This will reduce the cost of delivery of care, increase the time available to accept new referrals and enable them to provide high quality care for adults and pediatric patients."

In the Preface [10] of the proceedings of the $7^{\text {th }}$ annual event of the ICMCC in London, the editors expressed:

"The theme of the 2010 annual event is "Personal Health - Intelligent solutions to serve empowered patients". The seventh ICMCC annual event addresses the active participation of the citizen in his or her health and care pathway with the interactive use of Information and Communication Technologies, in other words; Patient 2.0 Empowerment as defined by ICMCC in 2008. The 2010 Event intends to combine ontologydriven health information system design for advanced interoperability with the paradigm change towards pervasive person-centric care, including prevention, home care, and wellness, together forming adaptive distributed health information systems solutions. Important issues to be considered are virtual Electronic Health Records and Personal Health Records acting as semantically interoperable communication and cooperation platform for personalized ubiquitous health services in a reliable environment."
It is relevant to mention that by 2010 , with the addition of one of the most comprehensive linked scientific articles data base, the system developed by Lodewijk was being accessed by about 134,000 unique visitors.

\section{The current special issue}

During the 2015 "Toronto" World Congress on Biomedical Engineering and Medical Physics, I organized a workshop with invited individuals that form the core of this special issue of the Journal. The IEEE Society for Social Implications of Technology was one of the technical cosponsors of this session.

Some of the authors of this special issue collaborated and aided Lodewijk in editing the proceedings of the ICMCC Events; some were additionaly members of ICMCC Executive Board, while others were part of ICMCC Advisory Board. One of the participants of the World Congress on Biomedical Engineering and Medical Physics in Toronto, Dr. Laura Roa, suggested that a Journal's Special Issue dedicated to the memory of our friend and colleague, Lodewijk Bos be arranged. That idea was then advanced, and Dr. Cari Borrás, a world-class medical Physicist was invited to be the Guest Editor of the Issue.

The Papers within this Special Journal Issue represent powerful concepts and constructs in which Dr. Lodewijk Bos had a significant interest, and professional commitment. Through his involvement and commitment, he motivated and challenged all of us to think differently, and to be more caring and impacting in our actions.

Finally, I would like to take this opportunity to thank all these colleagues for their contributions and Dr. Borrás for helping me putting this Special Issue together.

Luis Kun

Editor in Chief

\section{References}

1. Kun L, In memoriam-Eulogy to Lodewijk Bos. Heal Technol. 2015; 4:295-298.

2. Future visions of biomedicine and bioinformatics, In: A Liber Amicorum in memory of Swamy Laxminarayan. Communications in Medical and Care Compunetics Series. Springer Verlag; 2011

3. Patient expectations in the digital world. In: Future visions of biomedicine and bioinformatics. Communications in Medical and Care Compunetics Series. Springer Verlag; 2011. p. 53-59.

4. ICMCC Record Access Portal.

5. Fisher B, Fitton R, Bos L. WHO recommendation on record access (draft). In: Bos L, Blobel B, editors. Medical and care compunetics 4. Amsterdam: Ios Press; 2007. p. 311-5. 
6. Marsh A, Laxminarayan S, Bos L. Healthcare compunetics. In: Bos L, Laxminarayan S, Marsh A, editors. Medical and care compunetics 1. IOS Press; 2004. p. 3-11.

7. Bos L. Medical and care compunetics the future of patient-related ICT. In: Bos L, Blobel B, editors. Medical and care compunetics 4. IOS Press; 2007. p. 3-17.

8. Bos L. The impatient patient. In: Bos L, Blobel B, Marsh A, Carroll D, editors. Medical and care compunetics 5. IOS Press; 2008. p. 1-13.
9. Yogesan K, Bos L, Brett P, Gibbons M. Digital homecare-an introduction. In: J Nagel, editor. Handbook of digital homecare, series in biomedical engineering. 2009. p. 1-4.

10. Bos L, Blobel B. Preface. In: Bos L, Blobel B, Benton S, Carroll D, editors. Medical and care compunetics 6. IOS Press; 2010. p. V. 